\title{
ISRAEL UITWAARTS?
}

\author{
DR. D. J. BOOYSEN
}

\section{TER INLEIDING:}

Dit is moontlik om uit te gaan van verskillende standpunte wanneer daar gepoog word om die sendingmotiewe in die $\mathrm{Ou}$ Testament na te gaan en uiteen te sit. So is dit ook gedoen deur verskeie outeurs soos BLAUW, WRIGHT, BAVINCK, VAN DER MERWE en andere.

In die stuk wil ons die onderwerp beperk deur net enkele aspekte van die sendingperspektiewe aan te dui, en veral te let op die taak van Israel in die verband.

Dit is so dat daar versigtig met die gegewens te werk gegaan moet word sodat daar nie in die sendingywer meer in die $\mathrm{Ou}$ Testament ingelees moet word as wat daar in werklikheid staan nie. Aan die ander kant sal dit ook dwaas wees om dieselfde fout ie begaan soos daar wel vir baie jare gedoen is, en dit is om die Ou Testament heeltemal buite rekening te laat wanneer daar na Bybelse gegewens gesoek word in verband met die sendingtaak van die Kerk. Vanweë die besonder nasionale bewussyn van Israel en sy introverte gerigtheid is daar die mening gehuldig dat daar nie veel in die Ou Testament te sê is oor die sendingtaak van die besondere volk nie. WRIGHT het ook 'n poging aangewend om die probleme vir die Kerk aan te dui wat die Ou Testament skep omdat die Boek met bloed op soveel van die bladsye is. (13.27.)

Met die verloop van jare het daar 'n verandering van mening gekom in die verband en het daar nuwe belangstelling gekom vir die $\mathrm{Ou}$ Testamentiese gegewens. Die algemene gedagte wat gehuldig word is dan dat ons in die Ou Testament te make kry met die sentripetale, die middelpunttrekkende, sendingtaak; dit in teenstelling met die sentrifugale, soos laasgenoemde besonder sterk na vore kom in die Nuwe Testament. Dit wil ook vir my voorkom asof die standpunt sinvol en verantwoordbaar is.

\section{DIE SENTRIFUGALE SENDINGTAAK IN DIE OU TESTA- MENT:}

In die engere sin van die woord is dit nie korrek om van 'n sentrifugale sendingtaak in die Ou Testament te praat nie. Wanneer die verskillende standpunte teenoor mekaar opgeweeg word, dan kom BLAUW tot die gevolgtrekking: „First, it seems to me that both sides are agreed that never in the whole period of the old Testament was there any deliberate missionary activity. 
Even those who hold fast to a missionary interpretation of Deutero-Isaiah and Jonah recognize that the concern is for commissions and promises which will be realized only in the future. During the Old Testament period no one could arrive at mission as an act of going out for proclamation among the nations." (3.34.)

VAN DER MERWE deel in hierdie gedagtegang en ook hy stel dit duidelik dat aan Israel nie 'n spesifieke opdrag gegee is om die heilsboodskap uit te dra aan die volkere nie. (9.22.)

Daar is egter ook voorbeelde in die Ou Testament om aan te dui dat daar teenoor vreemdes getuig is dat die Here God is. Hierdie geleenthede was egter sporadies van aard en dit was ook elke keer individue wat opgetree het omdat hulle in bepaalde situasies beland het wat hulle daartoe gelei het om so te getuig. Rowley het Moses die eerste sendeling genoem. Uniek in die geval ten opsigte van ons studie is dat die aksie gerig was op sy eie mense in die eerste plek. So kan daar ook verder willekeurige voorbeelde in die Ou Testament aangedui word.

Josef gee te kenne dat hy mede-gevangenes van diens kan wees omdat die uitleg van die drome 'n saak van God is, Gen. 40:8. Eensgelyks getuig hy voor die Farao: „God sal Farao 'n gunstige antwoord gee." Gen. 41:16. In 2 Kon. 5:1 en verder lees ons van die geskiedenis van die klein dogtertjie wat as gevangene weggevoer was en in diens van Naäman se vrou gekom het. In die nood waarin Naäman verkeer het, het sy hom na die profeet in Samaria verwys. Die onwrikbare geloof van Daniëi en sy vriende in die God van hulle vaders is telkens bely teenoor die koning van Babel en onderdane, byvoorbeeld Dan. 2:27 v.v.; $3: 16$ v.v.; $4: 24 ; 5: 18$ v.v.; $6: 23$ v.v.

Hierdie gevalle kan ons nie sondermeer verstaan as sendingstake of -opdragte nie. Hier word die geloof van die betrokkene in die enige God van Israel bely. Belydenis van geloof hou vanselfsprekend verband met die verkondiging van die dade van God, maar in die gevalle is dit "sporadiese" optrede en nie primêr uitvoering van 'n spesifieke opdrag nie.

\subsection{DEUTEROJESAJA:}

Onder die verklaarders is daar verskil van mening oor die interpretasie van die gedeelte in die Skrif. BLAUW praat van missionêre hoogtepunte in die Ou Testament en verwys dan onder andere na die gedeelte. Hy beweer byvoorbeeld: „Almost all those who have been concerned with the question of the missionary message of the Old Testament are agreed that the universal significance and calling of Israel is nowhere expressed more clearly than here." (3.31.) Die missionêre profesië is veral 
opgeteken in die twee liedere van die Kneg van Jahwe, naamlik in 42:1-7 en 49:1-7. Dit is die taak van die Kneg om die reg na die nasies te bring, 42:1 en Hy is 'n Lig van die nasies, 42:6.

VRIEZEN lê besondere nadruk op die sendingkarakter van die gedeeltes. Volgens hom het Deuterojesaja besondere begrip aan die dag gelê vir die taak van Israel om die Tora aan die wêreld te bring. (12:45, 46). Hy beweer voorts dat aan Jes. 49:5, 6 te kort gedoen word wanneer die missionêre inslag van die boodskap van Deuterojesaja ontken word. Hier lê die sendingstaak van Israel in opgesluit. (12.487.) Hy gaan nie verder in op die probleem van die bring van die Tora of die uitvoering van die sendingsopdrag nie. Vanselfsprekend kom die vraag nou na vore hoe hierdie sendingstaak ten uitvoer gebring moet word? Klaarblyklik het hy hier die sentrifugale in gedagte en as dit so is, dan moet ons van hom verskil.

Wanneer daar dus van ",sendingsmotiewe" of "-opdragte" gepraat word ten opsigte van die Ou Testament moet dit nader gekwalifiseer word. Dit het LINDBLOM ingesien en in die bespreking van dieselfde onderwerp wat VRIEZEN behandel het, maak eersgenoemde die bewering: "The main themes of these revelations are the conversion of the Gentiles, Israel as an instrument of their salvation, and the preparation of Israel for the fulfilment of this task. These may be termed ,the missionary revelations." In 'n verklarende aantekening voeg hy dan by: „The expression ,missionary' must not be misunderstood. ,Mission' means here that Israel is charged with the mission to enable the Gentiles to share in the eschatological salvation. The modern idea of mission is of course out of the question." (5.267.) Die hele aangeleentheid word kort en bondig deur VON RAD so opgesom: „Aber von einen ,Missionsgedanken' sollte man nicht sprechen, denn wenn Deuterojesaja Israel als einen ,Zeugen' für die Völker beleichnet (Jes. $53: 10 ; 44: 8 ; 55: 4$ ) so denkt er doch nicht daran, dass Israel Boten aussenden solle." (11.263.)

Uit die voorgaande is dit daarom duidelik dat daar wel uit die gedeelte afgelei kan word dat Israel 'n taak teenoor die ander volkere gehad het, maar dan nie soos dit soms verkeerdelik verstaan word nie. Daar is nie sprake van die uitstuur van boodskappers deur Israel om die besondere boodskap aangaande die Here hulle God uit te dra nie. Die taak van Israel in die verband moet daarom anders begryp word.

\subsection{JONA:}

Met die Bybelboek Jona wil dit voorkom asof ons op 'n ander terrein begin beweeg ten opsigte van die sendingstaak. Hier het ons dan te make met 'n ongehoorsame profeet wat 
dırek opdrag ontvang: „Maak jou klaar, gaan heen na die groot stad Ninevé en preek daarteen, want hulle boosheid het opgestyg voor my aangesig." Jona 1:2.

Die feit dat Jona weier kan tog begryp word wanneer daar in aanmerking geneem word dat hy na die hoofstad van Assirië, die aartsvyand van Israel, gestuur word. Maar meer nog: Juis omdat daar nie 'n „sendingsbesef” by die Israeliete teenwoordig is nie, het die opdrag vir hom vreemd voorgekom. Hy moes dit vreemd gevind het dat God aan heidene vergifnis moet skenk, en daarom het hy verkies om maar liewer te vlug. Die allegoriese verklaring van die boek moet afgewys word. Volgens die verklaring stel Jona die volk Israel voor en Ninevê die heidenwêreld. Wanneer Jona nou ontrou optree, is dit eintlik Israel wat ontrou is in sy taak en roeping teenoor die heidenwêreld. So word Jona in die vis Israel in die ballingskap; Jona weer vry op die land, Israel na die ballingskap. In die soort van verklaring word wel aan Israel 'n sendingstaak toegeskryf waarvolgens die volk dan moet „uitgaan" om die getuies van God onder die volkere te word. RIDDERBOS het dit afgewys, $(8.26,28$.) BLAUW is dieselfde mening toegedaan, (3.41.) en VON RAD sien dit ook anders in, (11.304.) Dit gaan in die besondere boek daarom dat die vryheid van Jahwe om Sy planne met die volkere deur te voer, onaangetas sal bly en dat Sy planne wel die hele wêreld insluit. Van die skielike universalisme in teenstelling met die besondere of die partikularistiese gesindheid van Israel is daar nie sprake nie, aldus VON RAD.

Die logiese gevolgtrekking waartoe ons moet kom, sal derhalwe daarop moet dui dat ook hier nie sprake is van die uitsending van Israel onder die volkere van die wêreld nie. Hoogstens is die besondere taak wat in alle opsigte omskryf was, gekwalifiseer was, aan ' $n$ bepaalde individu opgedra en tot 'n besondere volk gerig.

\subsection{GEVOLGTREKKINGS:}

Om die voorgaande nou saam te vat kan ons die volgende opmerkings maak:

2.3.1. In die Ou Testament is daar wel sprake van missionêre tendense, maar ons sal nog meer duidelikheid daaroor moet kry voordat ons tot 'n finale gevolgtrekking kan kom.

2.3.2. Die enkele gedeeltes wat ter sake is dui nie op 'n algemeen-aanvaarde gedagtegang onder Israel nie. Die sporadiese optrede van individue kom ook veel sterker op die voorgrond as die van die volk in die algemeen. 
2.3.3. Daar is nie sprake van die sentrifugale sendingmetode in die Ou Testament nie. Ons kan opsommenderwys CRAFFORD aanhaal: „Israel se taak is eerder om soos 'n spieël die heerlikheid (iig) van God te weerkaats na die nasies. Dit is wat die begrip ,lig van die nasies' beteken in Jes. 42:6 en 49:6. Israel leef vir die nasies in sover Jahwe in hom leef. J. Blauw omskryf hierdie bevinding met die onderskeiding van twee begrippe, naamlik sentripetaal missionêr en sentrifugaal missionêr. In die Ou Testament kom slegs eersgenoemde voor." (4.8).

2.3.4. Die belangrikste gedeeltes wat hier ter sake is, soos Deuterojesaja, bevestig die sentripetale inslag van die sendingaksie. Israel sal 'n lig wees vir die nasies!

\section{DIE SENTRIPETALE SENDINGTAAK VAN ISRAEL IN DIE OU TESTAMENT:}

Van wesenlike belang is die feit dat Jahwe God is van alle nasies. Die klassieke Psalm 24:1, 2 stel dit kort en bondig: „Die aarde behoort aan die Here en die volheid daarvan, die wêreld en die wat daarin woon; want Hy het dit gegrond op die seë en dit vasgestel op die strome." Hierdie tema kom telkens terug in die Skrif, byvoorbeeld Eks. 19:5; Deut. 32:8, 9; Jos. 2:11; die Here is God oor die hele aarde en alles en almal behoort aan Hom. Dit bring ook mee dat alle volke voor Hom verantwoording moet doen, (Ps. 82:89) want almal is aan hom verbonde.

Daar is verskillende teologiese aspekte wat nou hier verder ter sprake kan kom soos die roeping van Israel, Israel en die volkere, die verkiesing van Israel en dergelike meer. Om ons egter by die onderwerp te bepaal kan ons met die laaste onderwerp volstaan, omdat die ander aspekte tog ook daarin vervat is.

Die probleem waarvoor ons dan staan is dit: Het die verhiesing van Israel nou as ander pool gehad dat die ander volke verwerp is? Het die verkiesing van Israel plaasgevind ten koste van die ander volke? Hierop het VAN WYK'n duidelike antwoord gegee: „Hy is God van die volkere. Hy hou nie op om God te wees as sy volk ophou om volk te wees nie . . . Hy gebruik daardie volksbestaan in Sy plan met die volkere in die geskiedenis. Die volk van die verkiesing het daarom geen status nie, maar 'n bepaalde funksie." (10.83.)

Vir ons gaan dit dan om die besondere funksie van Israel in die wêreld.

God se handeling met die uitverkore volk Israel, het in die wêreld een groot doel: Sodat die volkere van die wêreld daarvan kennis sal neem. God se optrede, Sy doen en late met Israel, 
het plaasgevind ter wille van die volkere van die wêreld. In die verhouding tussen God en Sy volk is daar dan meer op die spel as net die besondere volk. Daar is verskillende uitsprake in die Skrif wat hiermee verband hou en ons verwys na enkeles: Jos. 4:24; 1 Sam. 17:46; Jes. 19:21; Ps. 77:15. Hieroor het OBERHOLZER die opmerking gemaak: „Die gedagte in al hierdie uitsprake is dat Jahwe se handeling met en ten behoewe van Israel steeds die wyer doel dien dat die nasies daartoe gebring sal word om Hom te ken (jd'). Jahwe handel met Sy volk voor 'n universele gehoor, nie alleen in die land wat $\mathrm{Hy}$ aan Israel gegee het nie, maar in alle lande waar Sy volk of lede daarvan kom. Hy is alleen God, en Sy mag is universeel in verlede, hede en toekoms." (7.258.)

In hierdie wêreld het Israel 'n taak om te vervul - om lig van die nasies te wees. Hier vind ons dus die sendingstaak van Israel in die wêreld. Hierdie taak is 'n besondere wat op hulle gelê is: Hulle moet in werklikheid so volk van God wees dat daardeur daar lig opgaan vir die volke. Die resultate moet inhou dat die ander volkere na Jerusalem sal gaan, juis omdat dit bekend is wat God aan en vir Israel gedoen het. Die eskatologiese karakter van die gedeeltes moet daarom ook nie uit die oog verloor word nie.

Jes. 2:3 illustreer duidelik die voorgaande: „En baie volke sal heengaan en sê: Kom laat ons optrek na die berg van die Here, na die huis van die God van Jakob, dat ons Sy weë kan leer en ons in Sy paaie kan wandel ... " Hierby sluit ook ander uitsprake aan soos die in Sag. 8:20, 21, 23; 14:16 en Miga 4; asook Jes. 55:5. BAVINCK het hierop die aandag gevestig toe hy geskryf het: ". . . het nieuwe, verheerlijkte Israël zal blijken te zijn het vergaderpunt, waarom die volkeren zich samentrekken." (1.34.) Wanneer ons nou Ps. 68:32 teen die agtergrond sien dan is dit duidelik dat die reaksie van die volkere spontaan sal wees.

Vir Israel het hier 'n probleem gelê. Hier kom die vraagstuk van Israel se afsondering weer na vore, want dit is tog ook so dat daar iets van die eksklusiewe in die geloof is. (Vergelyk maar WRIGHT se opmerking in die verband, (13.30.) oor die sinkretisme.) BAVINCK het oor die aangeleentheid beweer dat die dilemma vir Israel daarin gesien moet word dat hulle gevaar geloop het om sowel op politieke as geestelike vlak in die groot geheel van die wêreld van daardie tyd ingesluk te word. Die aiternatief was vir hulle: , . . . het moest zelf worden tot een levende kracht, die de volkeren trok binnen het licht van de heilsopenbaring van Israëls God." (1. 32.) 


\subsection{GEVOLGTREKKING:}

Die Ou Testament sien die taak van Israel nie sentrifugaal nie maar sentripetaal. Teenoor die volkere het Israel wel 'n taak maar dan so dat die volkere na Israel sal kom en so tot die aanbidding van die God van Israel te kom. Hy is trouens die God van die hele wêreld, daarom van al die volke. Hulle sal vanuit die duisternis na die lig toe kom en so die weë van die Here leer ken.

Die vraag is nou in hoe verre kan die voorbeeld vandag nog nagevolg word? Daarmee hang ook saam of die sentrifugale, soos dit veral in die Nuwe Testament geleer word, die opheffing van die sentripetale beteken? Ek glo nie so nie. Die opvallende is dat daar sekerlik ook 'n saak uitgemaak kan word oor die sentripetale sendingmetode in die Nuwe Testament. Veeleerder sal ons voorlopig die oplossing daarin moet soek dat die twee mekaar nie uitsluit nie, maar veeleerder aanvul. Interessant sa: dit ook wees om vas te stel of daar slegs van die sentripetale metode gebruik gemaak kan word.

\section{PROF. DR. E. S. MULDER:}

Vanweë die besondere geleentheid is dit miskien van pas om net ook te let in hoeverre die voorgaande strook met die opvatting van die geëerde hoogleraar. Om dit te doen kan ons let op sy doktorale proefskrif wat etlike jare gelede gepubliseer is. Tog is dit wenslik om by die nagaan van die aangeleentheid versigtig te wees. Dit wel om twee redes: In die eerste plek het hy hom nie doelbewus oor die angeleentheid uitgelaat nie, en in die tweede plek moet daar ook nie 'n bepaalde gedagtegang aan hom toegeskryf word sodat die teologie wat hy leer in 'n bepaalde skema pas nie. Dit sou uiters onregverdig teenoor hom wees.

Die onderwerp van sy proefskrif het hom egter enigsins geleen aan die ondersoek wat hier ter sake is, en het dit ook telkens aandag geniet.

Ons let op 'n paar uitsprake. Die eerste wat ons teenkom kry ons in die bespreking van Jes. 25:3. Prof. Mulder het so vertaal: „Daarom sal 'n sterk volk $U$ eer, 'n stad van geweldige nasies U vrees." (622.)

Hieroor merk hy dan op: „Na hulle ondergang sien hulle in Jahwe een wat sterker is as hulle en so kom hulle tot eer en vrees." (6.26.) Die volkere aanbid Jahwe as gevolg van die toedoen van Jahwe self. Dit gebeur nie deur die uitgaan van 
Israel onder die volkere met die getuienis aangaande die enige waaragtige God nie. Hierdie volkere erken Jahwe as God en die gedagte is by Jesaja ook aanwesig, aldus Prof. Mulder.

Die erkenning deur die volke is die werk van Jahwe. Sy dade noop die volke tot hierdie erkenning. Dit is ook die gedagtegang van die profeet Jesaja soos ons dit vind in Jes. 26:9 waaroor die opmerking gemaak is: „Namate Jahwe werk in die geskiedenis, ... erken die mense dat Hy die werkende God is. Namate cie gerigte oor die aarde gaan, leer die inwoners pas sy heilsorde ken." (6.43.)

Israel is ook in die heilsplan van Jahwe betrokke en het deel aan die besondere werk wat gedoen sal word. Die gedagte kom na vore in Jes. 27:6 waar Israel vereenselwig word met die wingerd wat sy ranke laat uitspruit oor die hele aarde en dit met sy opbrengs vul. Jahwe seën sy volk, hulle sal 'n seën op die aarde wees. Die verklaring hier kan die indruk wek dat ons hier met die sentrifugale sendingmetode te make het, omdat Prof. Mulder die uitdrukking gebruik: „ . . . die deur Jahwe geseënde volk sal ook die heilsgoedere uitdeel en deurgee aan die volke van die aarde." Hierteenoor moet opgemerk word dat daar nie verder ingegaan is op die wyse waarop Israel hierdie heilsgoedere sal uitdeel aan die volkere van die wêreld nie. Om dus hieruit enige afleiding te wil maak sal heel waarskynlik die subjektiewe benadering van die ontleder aantoon!

In die bespreking van die teologiese aspekte van die Jesajaapokalipse het die outeur dan heel logies tot die gevolgtrekking gekom dat Jahwe die Bewerker is van die heil wat in die eerste plek bestem is vir die volk Israel, maar ook vir die ander volke. $(6,112,113$.

Dit is verder duidelik dat die heil wat ook bestem is vir die ander volke deur die toedoen van Jahwe tot die volke kom. Dit wil dan enersyds lyk asof Israel daar geen deel aan het om die volke te laat deel in die heil nie. Dit is trouens Jahwe wat self die maaltyd berei vir die volke om by aan te sit, Jes. 25:6-12. (6.112.) Andersyds is dit weer so dat die volke sal optrek na die berg van die Here, Sion, om daar onderrig te kry en om die woord van Jahwe te verneem. (6.113.) 'n Ander opmerking is hier voorts ter sake: „As middel tot bekering van die heidene is Israel van belang." Tog wil dit vir my voorkom asof die sentripetale uitgangspunt in die sendingstaak van Israel in die gedagtegang van Prof. Mulder te bespeur is. Die opmerking word gemaak na aanleiding van die verdere uitwerking van die rol van Israel 
in die verhouding van die volke teenoor Jahwe. Ons kry in die verband dan die opmerking op bladsy 116: „Omdat Jahwe die God van Israel is, sal die ander volke hulle by Israel aansluit" Jes. 55:4, 5 .

\section{VERWYSINGS:}

1. BAVINCK, Dr. J. H.: Inleiding in de Zendingwetenschap, J. H. Kok n.v., Kampen 1954.

2. BLAUW, Dr. J.: Het Geding om de Wereld, Deel 1, Oude Testament, Maart 1960.

3. BLAUW, JOHANNES: The Missionary Nature of the Church, Lutterworth Press, London 1962.

4. CRAFFORD, D: Wêreldsending en Wêrelddiakonaat, ongepubliseerde D.D.-proefskrif, Universiteit van Pretoria, Pretoria 1966.

5. LINDEBlOM, J.: Prophecy in Ancient Israel, Basil Blackwell, Oxford 1965.

6. MULDER, E. S.: Die Tealogie van die Jesaja-Apokalipse, J. B. Wolters, Groningen, Djakarta 1954.

7. OBERHOLZER, J. P.: Die Kneg van die Here in die Ou Testament, ongepubliseerde D.D.-proefskrif, Universiteit van Pretoria, Pretoria 1966 .

8. RIDDERbOS, Dr. J.: De Kleine Profeten, J. H. Kok n.v. Kampen 1949.

9. VAN DER MERWE, Prof. dr. W. J.: Gesante om Christus wil, N.G. Kerk-uitgewers, Kaapstad-Pretoria 1967.

10. VAN WYK, W. C.: God, Yolk en Mens by die Profeet Amos, Ongepubliseerde D.D.-proefskrif, Universiteit van Pretoria, Pretoria 1966.

11. VON RAD, G.: Theologie des Alten Testaments, Band 11, Chr. Kaiser Verlag, München 1962.

12. VRIEZEN, Prof. dr. Th. C.: Hooflijnen der Theologie van het Oude Testament, H. Veenman en Zonen n.v. Wageningen 1966.

13. WRIGHT, G. ERNEST: The Old Testament Basis for the Christian Mission, 'n artikel opgeneem in The Theology of the Christian Mission, Edited by Gerald H. Anderson, SCM Press Ltd., Londen 1961. 